\title{
Percebendo diferenças no ensino e na aprendizagem de técnicas de dança contemporânea
}

Sylvie Fortin e Warwick Long*

Resumo: O propósito deste artigo é discutir as percepções de dançarinos em relação à integração da educação somática a técnicas de dança contemporânea a partir de uma perspectiva construtivista. O estudo analisou as experiências de oito dançarinos profissionais e pré-profissionais em aulas de dança que integravam a educação somática à técnica de dança contemporânea. Durante cinco dias foram registradas as percepções dos dançarinos em relação à integração do Método Feldenkrais - Consciência Através do Movimento ${ }^{\circledR}$ a técnicas de danca contemporânea. Foram utilizados os seguintes métodos de coleta de informações: observações participantes, discussões em grupo, registros de diários e entrevistas individuais. A partir de uma perspectiva construtivista e utilizando a análise temática, os pesquisadores procederam à interpretação das experiências dos dançarinos. A discussão dos resultados considerou a relação entre as vias somáticas de conhecimento e a pedagogia construtivista.

Palavras-chave: educação somática, ensino da dança contemporânea, construtivismo.

O Método Feldenkrais ${ }^{\circledR}$ é um dos vários métodos de educação somática utilizados atualmente por dançarinos, em instituições de treinamento pré-profissional, como uma abordagem conjunta ou complementar a métodos de treinamento tradicionais (Bober, 2004). Utilizando o movimento como meio, este método favorece o desenvolvimento do autoconhecimento mediante a auto-observação de comportamentos sensitivos e motores, podendo funcionar como um catalisador para o desenvolvimento das funções motoras. (Feldenkrais, 1949; Hanna, 1990; Wildman, 1990; Wildman, 1990; Ginsburg, 1999). Goldfarb (1993) diz que

* Sylvie Fortin é professora do Departamento de Dança da Université du Québéc à Montréal, no Canadá e Doutora pela Ohio University (EUA). Warwick Long é Mestre em Educação Física pela Otago University (Nova Zelândia)

Movimento, Porto Alegre, v. 11, n. 2, p.9-29, maio/agosto de 2005 
“o Método Feldenkrais consiste em uma compreensão sistêmica do design do corpo humano relacionado ao movimento, bem como uma pedagogia orientada para a percepção e para provocar transformações no modo como as pessoas se movem" (p. 1).

Práticas somáticas como o Método Feldenkrais ${ }^{\circledR}$ foram amplamente difundidas nos ambientes acadêmicos e profissionais de dança contemporânea. Diversos autores afirmam que a educação somática influencia no ensino da dança, na prática coreográfica, na melhoria da performance de dançarinos, sendo também utilizada na medicina da dança, como prevenção e tratamento de lesões (Fitt, 1998; Fortin, 1995). Há diversos estudos abordando a eficácia do Método Feldenkrais ${ }^{\circledast}$ em vários domínios da prática médica, mas há menos relatos no campo da dança (Harris, 1996; Ives, 1998; Stephens, 1999). Apesar do crescimento da educação somática nas áreas acadêmicas e educacionais em dança (Cardinal, 2000), há poucas pesquisas que investigam a relação entre a educação somática e a dança contemporânea a partir da perspectiva do dançarino. Este trabalho caracteriza-se tanto como uma pesquisa conduzida por professores que trabalham sobre sua própria prática pedagógica quanto uma investigação de viés construtivista a respeito de percepções de estudantes de dança. Portanto, este artigo busca responder às seguintes questões: Como dançarinos podem construir um ambiente somático para conhecerem a si próprios através do movimento? Quais as questões e ações pedagógicas que emergem de uma abordagem construtivista da educação somática e de técnicas de dança contemporânea?

Neste estudo nos situamos como educadores, que atuam tanto no ensino da dança na universidade quanto no ensino da dança em níveis profissional e pré-profissional, como companhias e conservatórios de dança. Sylvie Fortin é profissional certificada no Método Feldenkrais ${ }^{\circledR}$ e professora titular do Departamento de Dança da Universidade de Quebec, em Montreal; Ralph Buck é professor associado do Institute of Creative Arts and Industries da University of Auckland; e Warwick Long é profissional certificado no Método Feldenkrais ${ }^{\circledR}$, artista de dança profissional e professor em departamentos de dança em Universidades na Nova Zelândia e no Canadá. Este estudo é, portanto, influenciado por nossos históricos sociais, culturais, educacionais e profissionais.

Movimento, Porto Alegre, v. 11, n. 2, p.9-29, maio/agosto de 2005 


\section{Posicionamento epistemológico}

Do ponto de vista epistemológico, nossa principal referência é o construtivismo. Um dos pontos de vista do construtivismo a respeito da natureza do conhecimento presume que as realidades, se existem, apenas se configuram "sob a forma de múltiplas construções mentais baseadas socialmente e em experiências locais e específicas e dependentes, na sua forma e no seu conteúdo, das pessoas que as mantêm" (Guba, 1990, p. 27). Portanto, como mostra Schwandt (1994), as noções do construtivismo têm um amplo uso, mas são particularmente "moldadas pela intenção de seus usuários" (p. 119). O autor também sugere que "seres humanos não encontram ou descobrem o conhecimento, mas geralmente o constróem. Inventamos conceitos, modelos e esquemas para termos sentido da experiência e continuamente testamos e modificamos essas construções à luz de novas experiências" (Schwandt, 2000, p. 197). Uma abordagem construtivista da educação sugere que o conhecimento é construído a partir da experiência pessoal, e que estilos e padrões precisos de ações individuais são desenvolvidos em um contexto social compartilhado que envolve o discurso, a linguagem e a ação corporal.

A abordagem somática da técnica de dança contemporânea que adotamos neste estudo está de acordo com a orientação epistemológica construtivista, pois se apoia na singularidade do indivíduo e na experiência sensorial distintiva de cada aluno como ponto de partida para desenvolver o autoconhecimento do corpo em movimento (Shusterman, 2002). Mais especificamente, o processo de construção do conhecimento neste estudo se fez investigando-se a integração do Método Feldenkrais ${ }^{\circledast}$ de educação somática a uma técnica de dança contemporânea, a partir da experiência vivida pelos alunos de dança e pelo professor pesquisador em uma série de aulas de dança, durante uma semana.

A pesquisa educativa, realizada pelo professor investigador, é definida por Cochran-Smith \& Lytle (1993), como uma “investigação sistemática e intencional efetuada pelos próprios professores" (p.7). Os autores destacam que "ensinar enquanto se pesquisa propicia uma visão construtiva, significativa e social da aprendizagem" (p. 101). Desse modo, este tipo de investigação é coerente com a perspectiva construtivista adotada neste estudo, já que são os professores e alunos que, juntos, delimi-

Movimento, Porto Alegre, v. 11, n. 2, p.9-29, maio/agosto de 2005 
tam o contexto no qual o ensino e a pesquisa ocorrem. Pode-se dizer que a pesquisa educativa compartilha certas características com a pesquisa-ação, em particular a idéia de que o desenvolvimento da consciência propicia a realização de ações sociais. Faremos referência à essa possibilidade posteriormente, pois os resultados surgidos no estudo indicaram possibilidades de transformação das ações dos participantes. No entanto, nosso estudo enfoca, principalmente, a compreensão da prática pedagógica em aulas de dança contemporânea.

\section{Coleta de dados}

A coleta de dados consistiu em gravações em vídeo das cinco aulas, discussões em grupo após cada aula, diários dos participantes, notas de campo do professor pesquisador e quatro entrevistas individuais de uma hora cada, abrangendo aspectos relacionados às histórias, às experiências e aos pensamentos dos participantes. Cada uma dessas fontes contribui de maneira diferente no processo de análise e interpretação. Os dados foram coletados em um programa de ensino superior em dança em Auckland, Nova Zelândia, em 2003. Um comitê de ética em pesquisa forneceu a aprovação ética, sendo que as questões éticas estavam relacionadas à manutenção do anonimato dos participantes, bem como sua segurança durante a participação na pesquisa. Todos os participantes assinaram um formulário de autorização e escolheram pseudônimos. Neste artigo, apresentamos os resultados de apenas quatro alunos, para que sejamos o mais fiel possível à experiência dos participantes e para que possamos analisar em profundidade esta experiência. Esse grupo é representativo, em termos de gênero e experiência, dos 16 alunos inscritos nas aulas diárias. Duas participantes (Amélia e Polly) eram estudantes de dança pré-profissionais matriculadas no curso de bacharelado, enquanto que os outros dois participantes (Bevan e John) eram dançarinos profissionais de uma comunidade independente de dança e freqüentavam as aulas mediante uma parceria da comunidade com a instituição. O processo de seleção para esses quatro participantes considerou os seguintes aspectos: histórico profissional e pré-profissional, gênero e profundidade na articulação do discurso de cada participantes. 


\section{Estrutura das aulas}

Cada aula tinha uma hora e trinta minutos de duração e consistia em quatro sessões distintas: a) a Consciência Através do Movimento; b) transição para pausa e caminhada; c) exercícios de técnica de dança; e d) combinações de seqüências coreografadas. Músicas gravadas e ao vivo eram freqüentemente utilizadas como acompanhamento. Após a conclusão da sessão de combinações de seqüências coreografadas, seguia-se um período de relaxamento e de discussão. A seguir apresentamos uma descrição detalhada das quatro sessões que compunham a aula.

\section{Consciência através do movimento (CAM)}

Essa sessão durava aproximadamente 20 minutos e era ministrada através de instruções verbais. O objetivo era concentrar a atenção na aprendizagem motora sensorial, mediante a introdução de uma série de lições de movimento que exploravam padrões fundamentais de movimento tais como flexão, extensão ou torção. Nessa parte da aula, os alunos deitavam-se no solo, a fim de diminuir os efeitos da gravidade e, assim, reduzir a atividade dos músculos posturais, bem como para favorecer a percepção e conscientização das atividades musculares parasíticas ou ocultas.

\section{Transição para posição de pé e caminhada}

Essa sessão durava aproximadamente 10 minutos e era orientada verbalmente. O objetivo era transferir o aprendizado das lições de CAM para funções simples como ficar em pé e caminhar, e, gradualmente, passar para funções mais complexas em dança.

\section{Exercícios de técnica de dança}

Essa sessão durava entre 20 e 30 minutos e era similar à aula de dança tradicional. Consistia em uma série de exercícios desenvolvidos para preparar o corpo para coreografias de dança mais exigentes tecnicamente, bem como para chamar a atenção para as exigências técnicas de alinhamento e precisão de movimento. Os temas e padrões das lições de CAM estavam presentes tanto nessa parte da aula quanto na combinação de seqüências coreográficas

Movimento, Porto Alegre, v. 11, n. 2, p.9-29, maio/agosto de 2005 


\section{Combinação de seqüências coreografadas}

Essa sessão durava entre 20 e 30 minutos e consistia em seqüências coreográficas mais longas, que incorporavam combinações dinâmicas de movimentos no espaço. Essas últimas duas sessões eram orientadas através de instruções verbais, demonstração visual e imitação do professor e dos próprios alunos.

\section{Métodos de análise de dados}

O objetivo da análise de dados era indicar possíveis respostas à nossa questão de pesquisa, no que diz respeito à percepção da integração da educação somática à técnica de dança contemporânea, na perspectiva dos estudantes. Após a transcrição e a revisão das entrevistas e dos diários dos participantes, a análise inicial da informação baseou-se em uma combinação de "codificação aberta" (Strauss \& Corbin, 1990) e método comparativo constante (Maykut e Morehouse, 1994). Utilizando tais processos e direcionando o foco da investigação para as duas questões específicas da pesquisa - Como dançarinos podem construir um ambiente somático para conhecerem a si próprios por meio do movimento? Quais as questões pedagógicas que emergem de uma abordagem construtivista da educação somática e de técnicas de dança contemporânea? - começamos a identificar significações e semelhanças entre os dados e a realizar comparações entre as diferentes informações coletadas. Desse modo, neste artigo a análise e a discussão dessas duas questões são apresentadas mediante a interpretação das experiências de duas dançarinas pré-profissionais - Amélia e Polly - e dois dançarinos profissionais - John e Bevan.

\section{Resultados e discussão}

\section{Modos somáticos de conhecimento}

O conhecimento somático é “o conhecimento sensível de si próprio que se desenvolve conduzindo a uma consciência que permite estabelecer relacionamentos mais significativos com o mundo"(Heshusius, 1994, p. 18). Os temas que surgiram da análise dos dados e que serviram para responder à primeira questão da pesquisa são listados abaixo, sustentados por observações específicas dos participantes da pesquisa.

Movimento, Porto Alegre, v. 11, n. 2, p.9-29, maio/agosto de 2005 


\section{Amélia. Acessando a essência do movimento: "você dança por um sentimento de prazer"}

A experiência inicial de Amélia com a integração do Método Feldenkrais ${ }^{\circledast}$ e a técnica de dança indicou uma certa frustração, mas também uma oportunidade a ser explorada a partir de uma perspectiva somática:

Estou-me encontrando com essas aulas, estou muito mais calma e, uma vez que começo a fazer as coreografias, posso sentir que compreendo o que meu corpo está fazendo e sei onde estou, e isso realmente me faz sentir bem. O que quero dizer é que há muita confusão; mas também, assim que entro nas coreografias, posso sentir onde está meu corpo, que estou me sentindo mais livre, e isso é muito bom. Sempre há aquele equilíbrio entre técnica e ojulgar a si mesmo e tentar ser melhor e só dançar livremente. E para que você dança? Por um sentimento de prazer.

Agora estou começando a trabalhar mais com o corpo, transferindo coisas de uma parte do corpo para outra, como aconteceu hoje com os pés. Achei aquilo realmente interessante: sentir mais algo que não seja só posição, posição, posição, mas que você possa criar algo, criar um alinhamento e criar um movimento no seu corpo usando outras partes dele. Eu tenho que não pensar no meu quadril para ser capaz de abrir meu quadril: isso é algo de que eu me dei conta muito rápido. Assim que penso na área, ela se tensiona. Então, se eu respirava, eu pensava talvez nos meus pés. Ou, se eu respirava, eu pensava em algo diferente, então daria certo. Eu descobri que eu conhecia o movimento tão bem quanto o sentimento que eu queria ter enquanto estivesse fazendo esse movimento. Eu não tinha que pensar tanto; e, mesmo assim, meu corpo parecia acessar o novo movimento, e parecia muito fácil.

Nesse exemplo, Amélia não se separa da dança na qual está engajada. A sua distinção entre o conhecimento do movimento e o sentimento de estar em movimento sugere que seu sentimento estético de movimento foi incorporado somaticamente. Para Amélia, a maneira somática de conhecer manifestou-se através da descrição de mudanças perceptivas na sua consciência, bem como pela utilização do tempo, de um modo que lhe permitisse assimilar o aprendizado. Assim, ela percebeu algumas transformações corporais, tais como uma mudança no seu alinhamento pélvico ou uma mudança na curvatura de suas costas. Os diários e as entrevistas de Amélia indicaram que as mais fortes expressões do conhecimento somático parecem manifestar-se em suas percepções de movimento e em diferentes experiências de estar no seu corpo:

Quando você me perguntou sobre como eu estava tentando corrigir meu osso sacro, era, na verdade, eu estava tentando ser capaz de sentiro que estava acontecendo. Porque eu não sabia onde meu osso sacro era, e ainda acho que não sei,

Movimento, Porto Alegre, v. 11, n. 2, p.9-29, maio/agosto de 2005 
mas estou começando a saber. Estou começando a ter uma imagem disso no meu cérebro, e tenho que obter isso a partir de uma variedade de fontes, como ver um desenho de um esqueleto; mas, talvez, para mim, ver uma imagem em duas dimensões nãome ajude muito: tenho que ver um esqueleto. Eu comecei a perder peso das minhas nádegas no ano passado e de repente consigo sentir onde estão meus ossos; nunca tive consciência dessa parte do meu corpo: é como se eu tivesse que aprender através de uma variedade de fontes que estavam dentro de mim antes que eu pudesse começar a mudar. Aconteceu a mesma coisa com minhas articulações do quadril: tive que aprender onde elas são e o que fazem dentro de mim, porque ainda tenho a idéia de que meu quadril está errado, por terem me dito que está errado; então tenho que reconstituir essa idéia em mim mesma.

Evidentemente, Amélia estava construindo uma imagem somática interna de si mesma. Como ela indicou, com o novo aprendizado, há freqüentemente confusão, mesmo que sua consciência e curiosidade continuem a conduzi-la a novas questões a respeito de si mesma. Uma das teoria da educação somática é a noção de que a integração da informação possa ocorrer abaixo do nível de um controle consciente; e que nosso soma, por meio da sua natureza auto-regulatória, gravitará em direção à solução ideal de uma tarefa, se lhe forem oferecidas as oportunidades corretas (Bernstein, 1967). Quanto mais clara a oportunidade no ambiente, mais fácil isso se dará. Entretanto, no caso de um movimento complexo ou fortemente habitual, as mudanças podem levar tempo. Ao tentarmos, conscientemente, controlar todos os aspectos do nosso movimento, como algumas vezes somos encorajados a fazer como dançarinos, talvez possamos, na verdade, inibir a oportunidade para que a integração ou a transferência ocorra. Freqüentemente, após uma aula do Método Feldenkrais ${ }^{\circledR}$, os alunos são instigados a perceberem quaisquer novas mudanças ou sensações no seu corpo, mas não a se prenderem obstinadamente a elas. O raciocínio por trás dessa noção é o seguinte: o que foi importante na aula fará sentido e será revelado no contexto da função, seja ela caminhar, dançar, escalar; não devendo ser considerado somente como uma sensação isolada. Prender-se a sensações novas e específicas, como um fim em si mesmas, pode ser contraproducente, já que essa consciência está focada somente na sensação e muito pouco na integração da sensação na função.

Polly. Explorando as possibilidades do corpo: "mudando movimentos habituais"

Polly referiu-se a um modo somático de conhecimento que se manifesta através de sua autoconsciência, de sua habilidade em criar outras possibilidades de movimento e de sua capacida-

Movimento, Porto Alegre, v. 11, n. 2, p.9-29, maio/agosto de 2005 
de em prestar atenção em hábitos de movimento desconfortáveis ou restritivos. No seu diário, no primeiro dia, Polly revelou detalhes da sua experiência:

Eu percebique estava de pécomo peso distribuído diferentemente sobremeus pés. No pé esquerdo, meu peso estava todo do lado de fora do pé; enquantono meu pé direito ele estava equilibrado. A distribuição de peso desequilibrada foi algo de que eu passei a ter consciência pelo resto do dia; e, enquanto caminhava, pude perceber que meu pé direito balançava para fora e depois para dentro quando eu dava um passo.

Freqüentemente, os alunos comentavam a respeito de suas diferentes percepções da postura após as aulas de CAM. É interessante ressaltar que a consciência de Polly de como o peso de seu corpo distribuía-se sobre seus pés permaneceu durante o resto do dia. A seguir, continuamos a discutir as diferentes percepções de Polly em relação ao primeiro e ao segundo dias de aula. No segundo dia, a aula sobre o tema "costela" fez mais sentido para a aluna, pois favoreceu alguns insights sobre as dificuldades apresentadas na seqüência coreográfica:

Eu me movi e fiz a primeira coreografia, e senti mais liberdade. Posso realmente mover minhas costelas sem cair, e isso me deu aquela noção de que há liberdade sem perda de controle. Eu acho que, por ter tido treinamento em balé, eu tenho certa tendência a segurar meu torso com muita tensão e controle e quando eu começo a me mover, e eu penso "oh, espera, eu vou cair" ou "estou perdendo o controle aqui".

Polly falou mais a respeito desta emergente consciência de hábitos e do desafio que é manter esta consciência e perceber quando esses hábitos impedem-na de dançar:

Essa semana realmente permitiu que eu pudesse ficar atenta à maneira como meu corpo faz o movimento; que maus hábitos eu tenho; onde estão minhas fraquezas; e que outras áreas eu posso enfocar para atingir o mesmo movimento. Eu senti um grande senso de verticalidade, e isso foi atingido a través do uso de menos ação muscular desnecessária. Eu comecei a achar novas maneiras de usar minhas pernas com grande liberdade e estabilidade, e tive uma sensação de liberdade e desenvoltura no meu torso. Eu percebi uma mudança significativa, especialmente no balé, onde minha tendência é segurar os músculos.

Ao construir um caminho somático para conhecer a si mesma através do movimento, Polly foi capaz de estabelecer relações entre suas experiências anteriores em dança e em movimento e os próprios processos de aprendizagem vividos nessa série de aulas. Ela também começou a identificar diferentes possibilidades de lidar consigo mesma, em analogia ao fato de que ela poderia, de diferentes maneiras, mudar o foco de atenção no seu corpo para realizar os mesmos movimentos.

Movimento, Porto Alegre, v. 11, n. 2, p.9-29, maio/agosto de 2005 


\section{John. Questionando por meio do nosso corpo: "quão consciente posso ser?"}

A criação e a apresentação de coreografias foram os meios pelos quais John construiu seu conhecimento somático. Ao coreografar e apresentar seu próprio trabalho, John explorou o tema "o que é ter um corpo" a partir de fundamentos da educação somática. Para John, as apresentações tornaram-se um veículo para expressar diferentes graus de consciência:

É quase como: Quão consciente posso ser? A quantos aspectos da minha realidade física eu posso prestar atenção, e então articulá-los? Eles podem ser visíveis?

No contexto das apresentações da coreografia, criou-se para John o desafio de poder dirigir a sua atenção como dançarino, e, ao mesmo tempo, poder direcionar a atenção do público para sua atuação. Através da sua experiência em ensaios e em apresentações, John fornece mais detalhes sobre o desenvolvimento de um modo somático de conhecimento.

No estúdio, se estou dançando sozinho ou, talvez, se estou improvisando, ou me apresentando, pode haver esse tipo de compromisso com o sublime ou odesconhecido... êxtase... eu não sei o queé, mas é como se eu estivesse perseguindo isso... a experiência divina ou algo assim. Então isso é provavelmente influenciado pela leitura do que diz Willian Forsyth, e eu acho que ele diz algo como dançar nos limites do sublime, ou écomo estar na pontomais extremo do que conhecemos ou como podemos perceberomundo.

Eu acho que, para mim, o trabalho com Feldenkrais é uma avenida para a exploração que pode levar a composições de movimento ou a um modo de criar movimentos interessantes. Eu tenho essa nova informação, mas não tenho certeza de como trabalhar com isso em pé, porque então tenho que ter mais um monte de conhecimento a respeito de como lidar com essa mobilidade extra. Algumas vezes eu fico muito entusiasmado ao pensar a respeito do Feldenkrais e tipo "oh, é essa coisa maravilhosa que vai mudar o mundo".

John apresentou uma experiência muito pessoal de um modo somático de conhecer o movimento e a dança. Contudo, como ele nos mostrou, a linguagem falada freqüentemente apresenta limites para a compreensão dos modos de conhecimento somáticos. Para John, e também para Amélia e Polly, a dança parece oferecer os meios mais potentes de expressar seu conhecimento somático. Sendo assim, as palavras foram ferramentas secundárias que puderam apenas abarcar uma parte do seu conhecimento somático. O uso da linguagem é uma das maneiras de expressar um modo somático de conhecimento. Nesse estudo, a representação das experiências dos alunos foi abordada

Movimento, Porto Alegre, v. 11, n. 2, p.9-29, maio/agosto de 2005 
através da linguagem, utilizando-se as discussões em aula, as entrevistas ou os diários. É interessante perceber que os participantes experimentaram uma certa dificuldade ao expressarem seu conhecimento somático por meio da linguagem. Essa dificuldade pode refletir a natureza profundamente pessoal da experiência de cada pessoa, bem como as inovações que esta abordagem do movimento proporcionou para cada um. Por outro lado, tal dificuldade pode também refletir o conflito que se estabelece ao tentar-se abordar as experiências somáticas a partir da natureza dualista e cartesiana da linguagem (Heshusius, 1994).

Howe e Berv (2000) estabeleceram relações entre linguagem e experiência utilizando as idéias de Wittgenstein, para quem o significado da experiência sensorial está associado, de forma interdependente, à construção lingüística. Wittgenstein, de acordo com Howe e Berv, afirma que "não há experiências sensoriais brutas... preexistentes às construções lingüísticas" (p. 23). Embora esta proposição de Wittgenstein seja discutível, ela é precedida pela idéia de que as comunidades lingüísticas nas quais nascemos estão impregnadas por dimensões culturais, históricas e sociais, que determinam os recursos e as práticas lingüísticas disponíveis. E não nos resta outra escolha a não ser apreendê-los (Howe e Berv, 2000). Dado que, como humanos, confiamos muito na linguagem, podemos também dizer que a linguagem tanto cria quanto limita nossas experiências do mundo. Apesar da linguagem ser o veículo pelo qual construímos significados sobre nosso aprendizado, nossa habilidade para expressar nossas sensações sobre o movimento também é limitada pela linguagem. A linguagem pode apenas aproximar-se dessas nossas experiências. Shusterman (2000) sugere que, freqüentemente, nossas experiências de movimento estão além do nível de linguagem, e que essa experiência é pré-linguística. "Algumas das coisas que experimentamos e entendemos nunca são capturadas pela linguagem, não por que a sensação particular destas experiências desafiem a expressão lingüística, mas porque não temos noção delas como coisas descritíveis" (p. 136). No contexto das aulas de dança, Fortin, Warwcik e Long (2002) destacam que a natureza dualista e cartesiana da linguagem inibe a habilidade de transmitir uma noção de "integridade da experiência" (p. 26). A idéia que fazemos de nós mesmos é socialmente construída através de nossas próprias experiências, que não se limitam à linguagem, mas se estendem também às interações sociais e às influências do ambiente que moldam nosso corpo e movimento. Shusterman (2000) sugere que " [...] esti-

Movimento, Porto Alegre, v. 11, n. 2, p.9-29, maio/agosto de 2005 
los individuais de falar ou de caminhar não são apenas diferentes entre si, mas são desenvolvidos através de práticas sociais de fala e de ação corporal, compartilhadas por um grupo. Não apenas a linguagem, mas até mesmo o estilo e os padrões precisos de nossos movimentos musculares são aprendidos em um contexto social" (p. 211). No ensino e na aprendizagem, as relações múltiplas entre sensação, movimento e linguagem são mutáveis.

Em resumo, essa discussão revelou como a parte da aula destinada ao Método Feldenkrais ${ }^{\circledast}$ não foi útil somente como um fim em si mesma, mas foi valiosa em relação à diversidade com que os alunos elaboraram maneiras extremamente pessoais de se movimentar e de desenvolver um conhecimento específico no contexto da técnica de dança.

\title{
Questões pedagógicas sobre construtivismo, educação somática e dança
}

Essa sessão apresenta alguns aspectos encontrados na literatura a respeito do construtivismo, relacionando-os aos seguintes tópicos: pesquisa educativa e professor investigador, pedagogia, educação somática e técnica de dança. Howe e Berv (2000) descrevem duas suposições fundamentais do construtivismo:

\begin{abstract}
A teoria construtivista da aprendizagem tem duas premissas básicas: a) a aprendizagem tem como ponto de partida o conhecimento do aluno, bem como suas atitudes e seus interesses levados à situação de aprendizagem; eb) a aprendizagem resulta da interação entre essas características e as experiências, de tal modo que os aprendizes constróem sua própria compreensão dos fenômenos de uma perspectiva interna e pessoal [como insiders] (p. 30-31).
\end{abstract}

Portanto, o facilitador de uma experiência educacional deve desenvolver uma compreensão das necessidades, das atitudes e dos pontos de partida dos alunos. Do mesmo modo, deve criar oportunidades de interações entre o conhecimento prévio e a experiência, permitindo a emergência de múltiplos modos de conhecimento.

Adotar a pedagogia construtivista "pura" tem seus problemas. Se um dos objetivos do aprendizado for a transformação do comportamento, simplesmente criar interações em torno da experiência existente pode não ser suficiente para transformar o comportamento ou para criar novos modos de conhecimento. Consequentemente, na pedagogia construtivista há a necessi-

Movimento, Porto Alegre, v. 11, n. 2, p.9-29, maio/agosto de 2005 
dade de associar-se à teoria de aprendizagem construtivista a técnicas de ensino não-construtivistas (Howe e Berv, 2000; McCarty e Schwandt, 2000). Um dos obstáculos para a aplicação da pedagogia construtivista "pura" reside no fato que os significados e as experiências que os alunos levam para as situaçõ̃es de aprendizagem nem sempre são precisos. Portanto, o desafio na abordagem construtivista é encontrar o equilíbrio entre o que deve ser valorizado e o que é pertinente para um crescimento rigoroso.

Um exemplo que ilustra esse desafio de balancear as diferentes abordagens de ensino apareceu no diário e na entrevista com Bevan. Em uma aula de dança tradicional, copiar o movimento do professor é o modo predominante de aprendizagem. Freqüentemente, o objetivo é copiar seus movimentos o mais precisamente possível. A partir disso, Bevan fez uma interessante observação que, ao mesmo tempo, valorizava a aprendizagem decorrente do conhecimento somático e a aprendizagem resultante da imitação visual do movimento.

É o desejo de mimetizar o estilo do professor. É isso que eu escrevia no meu diário no outro dia... uma vez chegou ao ponto onde eu tinha que fazer o movimento, eu pensava: como eu me mexo daquele jeito? Como se eu ainda quisesse ser capaz de atingir o que você estava propondo. Eu podia ver quando você mostrava a coreografia. O desejo principal é o de poder tentar e fazer aquela coreografia de um modo que preencha o desejo de fazer algo parecido. E não apenas fazer minha própria versão, uma versão completamente minha. Primeiramente, a coreografia é difícil mas adorável, então eu levo um tempo para perceber as coisas. Então, para mim, o que foi mais impressionante não foi o que fizemos no início da aula (pelomenos conscientemente), mas omodo como você fez a coreografia e o meu desejo de me mover tão claramente como vocêno seu movimento.

Isso é pertinente à luz da relação entre os objetivos externos e a compreensão interna do movimento. Na nossa entrevista, continuamos a discussão em torno da imitação do professor e da auto-exploração. Bevan disse que "como dançarino, é uma experiência adorável tentar dançar e dançar como outra pessoa porque você realmente se sente diferente". Bevan apresentou, concisamente, uma maneira de reavaliar os duplos benefícios obtidos ao copiar os movimentos do professor e, deliberadamente, explorá-los para definir o seu próprio estilo de movimento. Warwick, como professor investigador, concordou com Bevan e respondeu que, similarmente, tinha uma sensação de conquista quando conseguia interpretar o movimento de outra pessoa: "é como se eu achasse um novo modo de fazer algo". Isso destacou um paradoxo no ensino de Warwick: ele encoraja a autonomia, a

Morimento, Porto Alegre, v. 11, n. 2, p.9-29, maio/agosto de 2005 
autoridade pessoal e o pensamento crítico e, ao mesmo tempo, acredita que existe uma necessidade real de que, em algumas situações, se defina que "vamos fazer exatamente assim".

Questões semelhantes, pertinentes ao ensino e à aprendizagem do movimento, aparecem nas pesquisas sobre educação somática e dança. Vários autores criticam o uso da educação somática no ensino da dança, destacando alguns aspectos. O primeiro diz respeito à aparente diferença de contexto entre deitar no chão e experimentar movimentos mínimos vis à vis as exigências técnicas de um estilo estritamente prescrito e codificado como o balé clássico (Simpson, 1996). O segundo aspecto refere-se à valorização das práticas somáticas e à sua influência sobre a performance e a criação coreográfica. Nesse exemplo, Schultz (2000) questiona se essa tendência não conduz a um tipo de dança muito internalizada e introspectiva, em detrimento da técnica e da performance. Finalmente, de uma perspectiva estética, Brown (2001) sugere cautela em relação às "recentes tendências de práticas de dança inteligente" (p. 23). Disseminadas entre a comunidade de dança contemporânea, estas tendências preconizam o "corpo conhecedor", um corpo que deve ser fluente, mover-se sem esforço, estar solto e relaxado, sendo, para tanto, informado por disciplinas somáticas. A ênfase neste modelo de corpo dançante "retém um formalismo e uma pureza quase modernistas..." (p. 23). A nossa experiência também aponta para a possibilidade de que a educação somática transformese em um modelo ideal de "como mover-se", resultando em uma estilização e, talvez, em uma nova padronização do movimento dançado, sem preocupar-se em estabelecer nenhuma relação funcional com os modos de ser e de interagir no mundo. Ironicamente, isso contradiz o principal propósito da maioria das práticas somáticas, que tencionam trazer o movimento de volta à sua função, bem como favorecer a consciência de questões sociais mais amplas (Fortin, 2003). O argumento para contrapor-se a essas críticas não deve referir-se tanto ao processo somático, mas sim ao modo como um contexto favorável é criado (ou não é criado) pelos professores e alunos, a fim de estabelecer conexões entre os modos somáticos de aprendizagem e as exigências funcionais da criação coreográfica e da performance em dança.

Em contraste com essas críticas, muitos autores referem-se ao valor educacional das práticas somáticas. Esses autores propuseram uma revisão no modo tradicional como as aulas de dança têm sido ministradas em instituições de treinamento pré- 
profissionais. Em vez de um processo orientado para a obtenção de objetivos futuros, propõe-se a valorização das abordagens somáticas que enfatizam a primazia do processo nas experiências de aprendizagem do movimento. Sheets-Johnson (1979) utiliza-se deste argumento para preconizar mudanças no ambiente de aprendizagem, observando que métodos tradicionais de treinamento em dança são orientados para o futuro, pois "o movimento é, em geral, direcionado para onde eu ainda não estou" (p. 25). Em vez de enfocar o produto final do movimento, o melhor é trabalhar a partir da primazia da experiência, evidenciando a experiência de aprendizado. É somente através dessa experiência que o indivíduo é capaz de "discriminar e perceber mudanças" (p. 26). Como Sheets-Johnson define, "o momento em que se nota e discrimina a mudança é, claramente, um momento de aprendizagem" (p. 26). Blank (1987) e Lessinger (1996) também defendem a necessidade de que o treinamento de dança possibilite estimular e refinar o sentido cinestésico, a fim de facilitar alinhamentos corporais eficientes, em vez de confiar somente na imposição mecânica de correções provenientes de informações visuais objetivas.

A aprendizagem centrada em informações visuais objetivas também evoca uma abordagem centrada no professor. Baseado em dados empíricos, Green (1999) descreve o cenário tradicional de um estúdio de dança, onde "o professor apresenta movimentos específicos que exigem aprendizado mecanizado, enquanto os alunos esperam o elogio e a atenção do professor por meio da correção e da manipulação física; o professor é freqüentemente visto como uma autoridade especialista, que sabe de tudo" ( $p$. 81). Fortin, Long e Lord (2002) afirmam que o sentido visual têm sido, tradicionalmente, o principal caminho para o ensino e a aprendizagem da dança. Para os autores, um dos problemas desta abordagem, tanto para o aluno quanto para o professor, reside na possibilidade de o aluno traduzir o que ele vê em sensação cinestésica. Mediante a análise qualitativa dos dados da sua pesquisa, eles demonstram que existem diferentes maneiras de estimular a exploração de distinções cinestésicas através do uso do conhecimento processual como ferramenta que permite reproduzir e também comunicar as percepções de movimento do professor.

No presente estudo, a pedagogia construtivista mostra-se como um método efetivo para compreender as experiências dos alunos. Entretanto, os diferentes estilos de aprendizagem e as 
diferentes tarefas desempenhadas pelo professor durante as aulas exigiram, algumas vezes, a adoção de uma abordagem do ensino centrada no professor. Em conseqüência, foi necessário conjugar, às aulas que enfatizavam diferentes estilos de aprendizagem, algumas abordagens "não-construtivistas", conforme já ilustrado nas discussões prévias com Bevan. Howe e Berv (2000) argumentam em favor de uma abordagem plural para o construtivismo na educação, destacando que "[...] as técnicas pedagógicas construtivistas podem estar envoltas em uma epistemologia decididamente não-construtivista e vice-versa" (p. 20). Portanto, nessa perspectiva, as diferentes posições epistemológicas e as diversas técnicas pedagógicas não se encontram numa relação de exclusividade e nem são necessariamente incompatíveis entre si. Para Howe e Berv (2000), a essência da epistemologia construtivista pode ser encontrado na argumentação de Kant, para quem "um esquema conceitual sem dados sensoriais é vazio, e dados sensoriais sem um esquema conceitual é cego" (p. 21). Este ponto de vista é pertinente se considerarmos os dados sensoriais elaborados pelos alunos sobre seu próprio mover-se, num esquema constituído por aulas de técnica de dança.

Em técnicas de dança contemporânea, os passos técnicos de dança desprovidos de consciência sensorial podem tornar-se exercícios representacionais estéreis; por outro lado, supervalorizar a consciência sensorial à custa de função esquemática e técnica pode levar a um tipo de movimento nebuloso e introspectivo, conforme crítica realizada por Schultz (2000).

De acordo com Howe e Berv (2000), há reciprocidade entre nossa habilidade em utilizar e tornar significativo tanto os dados sensoriais quanto os esquemas conceituais. Os dados sensoriais não podem mais ser considerados dados brutos, assim como os esquemas não podem ser considerados puros, já que cada um só tem significado na construção da experiência. Em relação a esta pesquisa, as novas sensações experimentadas pelos alunos na parte da aula dedicada ao Método Feldenkrais ${ }^{\otimes}$ e as subseqüentes interações com a técnica de dança são consideradas como fenômenos interdependentes. Os princípios somáticos desprovidos de uma relação com a função são, de alguma forma, ilegítimos. A criação de um contexto que favoreça um ambiente de aprendizagem significativa é um dos mais importantes desafios da educação somática frente ao ensino da dança (Fortin, 2003).

Movimento, Porto Alegre, v. 11, n. 2, p.9-29, maio/agosto de 2005 


\section{Conclusão}

Se partimos do princípio que a educação diz respeito, em primeiro lugar, ao questionamento de nossos valores e do modo como vivemos no mundo, como a educação somática pode contribuir para a compreensão dos nossos valores e dos modos de nos movimentarmos em relação à técnica de dança contemporânea? Se a realidade na qual vivemos é permeada subjetivamente por significados e valores sociais e culturais, então nossos corpos também são locais para a representação de relações de poder construídas cultural e socialmente (Fortin, 2001). A noção de conhecimento somático torna-se um plexo, um quiasma, uma rede através da qual as relações de poder e as inscrição sociocultural ocorrerem.

De acordo com Shusterman, o corpo sensível é central para nossas interações no mundo. Em vez de se conformarem com o corpo dócil, dançarinos podem aprender, por meio da educação somática, a ter autoridade sobre como constróem ou mesmo transformam seus corpos individuais no contexto de diferentes - e sempre socialmente construídos - estilos de dança. Sendo assim, eles podem aprender a equilibrar a noção de um corpo construído e os valores internos e externos que podem nortear a construção deste corpo.

Através de sua evolução histórica, o ensino de técnicas de dança baseou-se, primeiramente, em várias teorias de conhecimento referenciadas na dança (dance-based knowledge). Ao longo do tempo, os dançarinos submeteram-se intensamente às exigências do fazer coreográfico ou às demandas de estilos técnicos (Stinson, 1998). As evidências deste estudo revelam que a compreensão da técnica, para os dançarinos, está ligada à exploração das relações entre sua própria consciência em movimento e as exigências ou limitações da técnica. A parte da aula dedicada ao Método Feldenkrais e a seção dedicada à técnica de dança acabam por se encontrar na seção de transição, que serviu como ponte para unir o mundo privado da experiência, vivida na prática do Método Feldenkrais ${ }^{\circledast}$, ao mundo social ou compartilhado que se manifesta na seção de técnica de dança. Neste momento, os alunos estabeleceram relações entre as sensações da sua experiência com Método Feldenkrais ${ }^{\circledast}$ e as exigências esquemáticas da aula de técnica de dança.

A estrutura da aula alternava o conhecimento referenciado na educação somática (somatic-based knowledge), na parte

Movimento, Porto Alegre, v. 11, n. 2, p.9-29, maio/agosto de 2005 
dedicada ao Método Feldenkrais ${ }^{\circledR}$, e o conhecimento referenciado na dança (dance-based knowledge), na etapa dedicada à técnica de dança. O objetivo da aprendizagem na etapa referente ao Método Feldenkrais ${ }^{\circledast}$ estava centrado na investigação de si mesmo através do movimento. Nessa parte da aula, o corpo de cada pessoa torna-se seu próprio ponto de referência sensorial, permitindo-lhe aprender e fazer distinções através do questionamento de suas próprias percepções de movimento. Um ambiente voltado à atenção externa tipificava a etapa voltada para a técnica de dança, em que os processos internos das atividades praticadas através do Método Feldenkrais ${ }^{\oplus}$ eram integrados aos processos externos de aprendizagem pela referência a outro corpo (seja o corpo do professor ou os corpos dos outros alunos). A etapa referente à técnica de dança evocava a relação entre os dançarinos considerados individualmente e os conteúdos de conhecimento presentes na técnica de dança. Essa relação estabelecia uma reciprocidade, identificada neste estudo como uma tensão dialética que deve ser administrada durante as aulas de dança tanto pelo professor quanto pelos alunos. A tensão se dá entre a construção de um conhecimento mais profundo de si mesmo em movimento e a maneira de integrar esse conhecimento às exigências funcionais da técnica de dança.

Em conclusão, podemos dizer que os alunos valorizaram uma variedade de abordagens para a aprendizagem de técnicas de dança contemporânea. Entretanto, todos destacaram a contribuição da educação somática como uma outra forma de desenvolver um conhecimento de si próprio em movimento. Isso não quer dizer que a educação somática seja incompatível com outros modos de aprendizagem. Conforme mostrado na análise das informações, muitos consideraram a abordagem somática confusa, parecendo, mesmo, uma ameaça a seus modos já estabelecidos de conhecer e entender a técnica de dança contemporânea. Contudo, a integração da educação somática à técnica de dança auxiliou os alunos a aguçarem a sensação e a compreensão mais detalhada sobre si próprios em movimento. Cabe destacar que esta integração da educação somática à dança se fez respeitando a emergência de diferentes estilos de aprendizagem, bem como incorporando abordagens pedagógicas centradas no aluno, assim como aquelas centradas no professor.

A presente pesquisa sugere alguns caminhos futuros a serem explorados, que podem incluir a utilização de um protocolo de pesquisa similar na área do balé clássico, a investigação das 
diferenças entre dançarinos profissionais e pré-profissionais, e a investigação de uma aplicação específica da educação somática no processo de criação coreográfica.

\begin{abstract}
The purpose of this article is to discuss dancer's perceptions of the integration of somatic education and contemporary dance technique from a constructivist perspective. The study examined eight professional and pre-professional dancers' experiences of Feldenkrais Awareness Through Movement ${ }^{\circledR}$ lessons, integrated within a daily contemporary dance technique class. Dancers' perceptions of experiences over five days of classes were gathered through participant observation, group discussions, journal entries and individual interviews. A constructivist position informed the researchers interpretation of dancers' experiences which were examined through thematic analysis. Results are discussed in relation to somatic ways of knowing and constructivist pedagogy. Keywords: somatics, contemporary dance teaching, constructivism.
\end{abstract}

\begin{abstract}
Resumen: El propósito del artículo es hacer una discusión sobre las percepciones de bailarines en relación à la integración de la educación somática con las técnicas de danza contemporánea a partir de una perspectiva constructivista. El estudio analizó las experiencias de ocho bailarines profesionales y pre-profesionales en clases de danza que integraban la educación somática a la técnica de danza contemporánea. Por cinco días fueron registradas las percepciones de los bailarines en relación a la integración del Metodo Feldenkrais - Conciencia A Través Del Movimiento ${ }^{\circledR}$ con las técnicas de danza contemporánea. Fueron utilizados las siguientes técnicas de coleta de información: observación participante, discusiones en grupo, registros en diarios y entrevistas individuales. A partir de una perspectiva constructivista y utilizando el análisis temático, los investigadores han procedido la interpretación de la experiencia de los bailarines. La discusión de los resultados consideró la relación entre las vías somáticas del conocimiento y la pedagogía constructivista.

Palabras clave: educación somatic, enseñanza de la danza contemporánea, constructivismo.
\end{abstract}

Movimento, Porto Alegre, v. 11, n. 2, p.9-29, maio/agosto de 2005 


\section{Referências}

BERNSTEIN, N. (1967). The Co-ordination and Regulation of Movements. London, Permagon Press.

FELDENKRAIS, M. (1949). Body and mature behaviour. London, Routledge and Kagan.

FORTIN, S., LONG, W. E LORD, M. (2002). Three Voices: researching how somatic education informs contemporary dance technique classes. Research in Dance Education, v. 3, n. 2, p.155-179.

GINSBURG, C. (1999). "Body-image, movement and consciousness: Examples from a somatic practice in the Feldenkrais Method." Journal of Consciousness Studies 6(2-3): 79-91.

GREEN, J. (1999). "Somatic Authority and the Myth of the Ideal Body in Dance Education." Dance Research Journal 31(2): 80-100.

HANNA, T. (1990). "Clinical Somatic Education: A New Discipline in the Field of Health Care." Somatics, Magazine-Journal of the Bodily Arts and Sciences Volume VIII( No. 1 Autumn/Winter).

HARRIS, S. (1996). "How Should Treatments Be Critiqued For Scientific Merit." Physical Therapy 76(February): 175-181.

IVES, J., SHELLEY, G (1998). "The Feldenkrais Method in rehabilitation: a review." Work A Journal of Prevention Assessment and Rehabilitation 11: 7590.

MAYKUT, P. and R. MOREHOUSE (1994). Beginning Qualitative Research: A Philosophic and Practical Guide. London, Falmer Press.

SIMPSON, M. (1996). "Dance Science: A Second Step Approach." Impu/se 4(1): $1-5$.

STEPHENS, J. (1999). "How Does the World Evaluate Research on the Feldenkrais Method." in Touch (Third quarter): 12-13.

WILDMAN, F. (1990). "The Feldenkrais Method: clinical applications." New Zealand Journal of Physiotherapy 18(2): 9-10.

WILDMAN, F. (1990). "Learning - the missing link in physical therapy: a radical view of the Feldenkrais Method." New Zealand Journal of Physiotherapy 18(2): 6-7.

Movimento, Porto Alegre, v. 11, n. 2, p.9-29, maio/agosto de 2005 
Recebido em 05/01/2005 Aprovado em 10/02/2005

Sylvie Fortin Université du Québec à Montreal Departament de danse Case Postale 8888, succursale Centre-ville Montreal (Québec)

Canadá E-mail:

fortin.sylvie@uqam.ca

Movimento, Porto Alegre, v. 11, n. 2, p.9-29, maio/agosto de 2005 